\title{
You are what you wear: Brand personality influences on consumer impression formation
}

\author{
Bob M. Fennis *, Ad Th. H. Pruyn ${ }^{1}$ \\ Department of Marketing Communication and Consumer Psychology, University of Twente, \\ P.O. Box 217, 7500 AE, Enschede, The Netherlands
}

Received 1 October 2005; received in revised form 1 April 2006; accepted 1 June 2006

\begin{abstract}
The present study examines the role of brands in the process of impression formation. The article examines the hypothesis that brand personality traits may carry over and affect perceptions of the personality of the brand's owner. Based on the continuum model of impression formation the findings support the expectation that the impact of brand personality is stronger when the situational context embedding brand and owner is consistent with the key association that the brand evokes. Moreover, the amount of attention the perceiver can devote to the judgment task moderates this process, such that the interaction effect between brand personality and situational consistency is more pronounced when consumers are free to use as much time to the impression formation task as deemed necessary. Conversely, when under time pressure, consumers tend to resort only to brand personality as a basis for forming an impression.
\end{abstract}

(C) 2006 Elsevier Inc. All rights reserved.

Keywords: Impression formation; Brand personality; Consumer personality; Continuum model; Consumer perceptions

\section{Introduction}

Imagine a middle-aged man driving a Porsche 911 along The Strip in sunny Las Vegas. Now picture another middle-aged man driving a Ford Pinto along the same road. What do you see? What kind of men are they? Do you think they have a lot in common? Or do you see important differences between them, for instance with regard to their preferences, lifestyles and personalities? To the extent that the latter is the case, your perceptions support the notions outlined and tested in this paper. That is, the current study investigates the relationship between a brand's personality (Aaker, 1997) and the personality of its owner. The present article argues that salient brand personality dimensions may affect consumer perceptions of personality traits of the owner of the brand. An effect exists involving the transfer of brand personality traits to consumer personality traits via a process of impression formation.

\footnotetext{
* Corresponding author. Tel.: +31 53489 4051; fax: +31 534894259 .

E-mail addresses: b.m.fennis@utwente.nl (B.M. Fennis), a.t.h.pruyn@utwente.nl (A.Th.H. Pruyn).

${ }^{1}$ Tel.: +31 53489 2769; fax: +31534894259.
}

The following section reviews the evidence on the concept of brand personality and its relationship with human personality traits, as well as the role salient brand personalities may play in impression formation processes. Section 3 presents an experiment that tests the potential of a brand personality dimension to affect the perception of the personality of the brand owner in the eyes of an external observer.

\section{Brand personality and human personality}

In analogy to the five factor structure of human personality (i.e., the "Big Five", Goldberg, 1992), Aaker's (1997) scale taps the dimensions of a brand's personality. In a series of studies, Aaker demonstrates that brands can be described in terms of salient personality traits similar to individuals and that, similar to the Big-Five of human personality, five basic brand traits can be discerned, namely sincerity, excitement, competence, sophistication, and ruggedness. In subsequent studies, the concept of brand personality has proven helpful in explaining the relationships between people and their brands. For instance, Aaker (1999) demonstrates that people tend to select and use brands with different salient personality dimensions to "highlight" certain 
aspects of their own personality in various situational contexts. Especially for high self-monitoring individuals (highly prone to social cues), her results show that traits that are made accessible by situational cues may affect consumer's brand choice and that different traits that are made salient, can have different effects on brand attitudes based on the brand's personality. In addition, more recent studies on the relationship between brands and people (Aaker et al., 2004) show that brand personality traits can have a direct influence on the way the relationship between brand and owner is formed and maintained. That is, Aaker et al. (2004) finds that in line with implications of the brand personality concept, relationships with sincere brands deepen over time, whereas consumer-brand relationships for exciting brands show a more short-lived, "fling-like" development over time.

Note that in these studies, brand choice, brand attitudes and consumer-brand relationships constitute the dependent variables, and personality traits of the brand's owner play a role as a causal factor, albeit in interaction with situational factors. This leaves open a rather straightforward, but as yet unaddressed question in the marketing and consumer behavior literature: what happens when roles are reversed and a salient brand personality functions as an independent variable? Can brand personality attributes then affect aspects of the self of the owner, either directly, or in the eyes of an external perceiver? To date, this issue has received no systematic scholarly attention. There is, however, ample reason to assume that they can. For instance, from an interpretative perspective, seminal work on the extended self (Belk, 1988) underscores the notion that people's possessions do not leave their self-concept unaffected. Instead, products and brands are posited to be interwoven with the very fabric of life to such an extent that they continually shape, reinforce and codetermine the individual's sense of who he or she is, and they play an important role in the consumer's progression through various stages in life (Belk, 1988; Fournier, 1998). Moreover, Fennis et al. (2005) recently demonstrated that salient brand personality dimensions can directly impact the aspects of the self-concept, based on the notion of the 'malleable self': the idea that the self is not invariant across situations, but instead is amenable to situational influences, of which brands are but one example (see Markus and Kunda, 1986). In a series of four experiments, Fennis et al. (2005) find that brand personality dimensions could influence self-perceptions of Big-Five and related factors, even when consumers are not the brand owners, but are only accidentally exposed to these brands. For instance, this research shows that brand sincerity affects self-perceptions of agreeableness and brand ruggedness influences self-ratings of extroversion. Moreover, exposure to exciting brands influences self-perceptions of hedonism, and exposure to competent brands induces higher self-ratings of sophistication. In short, these and earlier studies underscore the notion that "we are what we wear" (cf. Belk, 1988).

\subsection{Brand personality and impression formation}

Can these results be extended to the realm of consumer impression formation? Stated differently, do consumers use salient brand personality dimensions to infer personality traits of the owner of the brand? A "classic forerunner" of the present research suggests that they do. In an early discussion on projective techniques in marketing, Haire (1950) argues that attributes of products on a shopping list could influence perceptions of the presumed owner of the list. Contemporary frameworks on impression formation support this notion. More specifically, the continuum model of impression formation (Fiske and Neuberg, 1990; Fiske et al., 1990) states that, as a function of the extent of motivation and/or ability, perceivers may form impressions of a target along a continuum, ranging from quick-snap, instant categorizations of the target, to effortful, piecemeal integration of all available information with regard to the target. As building blocks of this impression formation process, the perceiver will use salient features of a target either as simple category labels or as attribute information.

Importantly, although earlier work focuses on clearly distinctive physical cues such as ethnic background or gender for impression formation (see for example Biernat and Vescio, 1993; Hewstone et al., 1991), the continuum model would hold that any salient feature may be used to the extent it is deemed a "valid" and "diagnostic" cue in evaluating the target. Hence, to the extent that brand personality dimensions are salient to perceivers, they may be used as either simple category labels or as attribute information in the process of impression formation. Of the five brand personality traits conceptualized by Aaker (1997), the current study focuses on the role of brand competence. Thus, based on the logic underlying the continuum model, the perception of brand competence will carry over to affect the perception of competence of the brand's owner (hypothesis 1).

\subsection{Qualifiers in impression formation}

Fiske and others (e.g., Fiske and Neuberg, 1990; Fiske and Leyens, 1996; Levine, Halberstadt and Goldstone, 1996) emphasize that simple and straightforward categorizations are not always the endpoint in the impression formation process, but that the availability of category labels plus category-consistent information sometimes qualifies categorization. Related work in information processing and persuasion (Aaker and Sengupta, 2000; Maheswaran and Chaiken, 1991; Maheswaran et al., 1992) underscores that the perceived validity of category labels or cues is also a function of the information that the surrounding context conveys. More specifically, cues are diagnostic and valid to the extent that their meaning is congruent or consistent with this context (cf. Aaker and Sengupta, 2000). Stated differently, the likelihood that impression formation involves a given label increases to the extent that the key association evoked by the label matches the association evoked by its context. Conversely, labels are less prone to be used in impression formation when there is a mismatch in association between label and context. Given the fact that the setting in which a target is situated carries information that may be relevant for impression formation in addition to a salient brand personality, the present research forwards the hypothesis that situational context moderates the effect of brand personality on perceptions of the personality of its 
owner. More specifically, the impact of brand competence on perceptions of the target's competence will be stronger when the situational context is consistent with the perception of brand personality than when the situational context is inconsistent (hypothesis 2).

This interaction between a brand's salient personality and the situational context points to an impression formation process that requires more attention from the perceiver than what would be required when basing one's judgment solely on the brand label. Fiske et al. (1990) suggest that any process involving the integration of various pieces of information to arrive at an evaluation of a target will move the perceiver away from the basic categorization pole of the impression formation continuum, and in the direction of the more individuating pole, where judgment involves careful, piecemeal processing of all available information about the target. For the present study, this yields the third hypothesis. That is, the aforementioned interaction between brand competence and situational context on perceptions of the target's competence will be more pronounced when the perceiver can devote considerable attention to all components in the impression formation process (i.e., the situation, the brand, and the person to be evaluated). When the amount of attention is limited (in the present study because a time constraint restricts the perceiver in devoting a considerable amount of careful attention to the impression formation task), judgment is based solely on simple category labels. Hence, in the latter case, impression formation is largely a function of brand personality.

\section{Method}

\subsection{Overview and participants}

This study tested the hypotheses in a 2 (brand competence: high/low $) \times 2$ (situational context: consistent/inconsistent $) \times 2$ (time constraint: present/absent) between-subject factorial design. A total of 314 individuals (156 male and 158 female) with a mean age of 22 years $(\mathrm{SD}=2.24)$ participated voluntarily in the experiment. Participants received no money, course credit or other incentives. In a vignette study, participants were presented with written instructions (on a computer screen) and were asked to imagine themselves in a specific situational context in which they lose their way. In this setting, they imagined encountering an unfamiliar male individual, whom they were requested to ask for directions. The person in question wore a neutral sweater which prominently displayed the experimental brands (see below). He was depicted on the screen containing the instructions and his bodily posture, ethnic background and all other idiosyncratic physical attributes were held constant across all experimental conditions to prevent any design confound. After imagining themselves in this scenario, all participants were asked to form an impression of this individual. To this end, they completed a questionnaire consisting of several traits that the person was perceived to possess. Finally, the study ended by debriefing the participants and thanking them for their participation before being dismissed.

\subsection{Independent variables}

\subsubsection{Brand competence}

For the manipulation of brand competence, a pilot study was conducted. In this pilot study 40 individuals, acting as judges (mean age $=24.5$ years, $\mathrm{SD}=3.33$ ) rated 50 familiar brands of clothing that were actively marketed at the time of study. These judges were not involved as participants in the actual experiment. Each of the brands was rated on the dimension of competence of the "Brand Personality Scale" (Aaker, 1997), which consisted of 9 adjectives. For each of the adjectives, participants indicated the extent to which they thought that particular adjective was descriptive of the brand $(1=$ not at all descriptive, $5=$ fully descriptive, $\alpha=.90$ ). Sample adjectives included 'successful', 'intelligent', and 'confident' (see Aaker, 1997 for a complete listing of the adjectives). For each brand, a competence score was calculated by averaging the scores on the individual adjectives, resulting in a competence index. For the present study, the brands that were selected were those with the highest and lowest competence index ("Boss" and "Australian", respectively). Analysis of variance confirmed that "Boss" induced significantly higher competence ratings $(M=3.98$, $\mathrm{SD}=.64)$ than "Australian" $(M=2.19, \mathrm{SD}=.50, F(1,39)=$ 92.93, $p<.001, \eta^{2}=.72$ ). Hence, in the high competence condition, the male individual depicted in the vignette wore a sweater prominently displaying the "Boss" logo (termed the 'competent brand'). More specifically, this included the word "Boss" in caps with "Hugo Boss" positioned underneath it in a smaller font. In contrast, in the low competence condition, the sweater bore the "Australian" logo (termed the "incompetent brand'). This entailed the word "Australian" and a kangaroo symbol. In both conditions, the type and color of the sweater and the size of the brand logo were held constant.

\subsubsection{Situational context}

The situation in which the participant imagined him or herself was varied such that in the consistent condition, the key association evoked by the context setting matched the association evoked by the brand. In the inconsistent situational context there was a clear mismatch in associations between brand and setting. To ascertain that the association the context evoked either matched or mismatched that of the brand, a second pilot study was conducted, akin to the one for the brand competence manipulation. In this pilot study, two situational contexts, a golf course and a camping site, were rated by 34 judges (mean age $=22.1$ years, $\mathrm{SD}=1.72$ ), that were not enrolled as participants in the actual experiment. Judges rated both situational contexts on the same dimension of competence of the Brand Personality Scale (Aaker, 1997) as used in the brand competence pilot test. For each of the 9 adjectives, participants indicated the extent to which they thought that particular adjective was descriptive of the situation $(1=$ not at all descriptive, $5=$ fully descriptive, $\alpha=.87$ ). For each situation, a competence score was calculated by averaging the scores on the individual adjectives. Analysis of variance indicated that the golf course was rated significantly higher in competence $(M=3.58$, $\mathrm{SD}=.61)$ than the camping site $(M=2.57, \mathrm{SD}=.53, F(1,33)=$ 
47.50, $\left.p<.001, \eta^{2}=.59\right)$. Hence, the consistent situational context for the competent brand entailed the golf course. For the incompetent brand the camping site was selected as the consistent situational context. In the inconsistent situational context, both situations were reversed to create a mismatch with the brands concerned (i.e., Boss within the context of a camping site and Australian embedded in a golf-course context).

\subsubsection{Time constraint}

To vary the extent to which participants could thoughtfully process the information in the vignette, a time limit was either present or absent. In conditions where a time constraint was absent, subjects were free to devote as much time to the impression formation task as they needed. In contrast, in conditions where a time constraint was present, participants were granted only $6 \mathrm{~s}$ to arrive at an evaluation of the individual featured in the scenario.

\subsection{Dependent measure}

\subsubsection{Perceived competence}

The extent to which participants judged the individual described and depicted in the scenario as competent was assessed using the traits that comprised the competence dimension in the Brand Personality Scale (Aaker, 1997), adapted to be suitable for assessment of impressions of an individual, instead of a brand. More specifically, subjects rated the person in the description on 9 adjectives on a 5 -point Likert scale $(1=$ not at all descriptive, $5=$ fully descriptive): reliable, hardworking, secure, intelligent, technical, corporate, successful, leader and confident. An index of perceived competence was formed by averaging scores on these traits $(\alpha=.73)$.

\section{Results}

Data were analyzed using a 2 (brand competence) $\times 2$ (situational consistency) $\times 2$ (time constraint) full factorial ANOVA. The analyses yielded the following results. First, supporting hypothesis 1, a main effect of brand competence indicated that the individual associated with the competent brand (i.e., Boss) was rated as more competent $(M=3.58, \mathrm{SD}=.39)$ than when he was associated with the incompetent brand (i.e., Australian, $M=3.24, \mathrm{SD}=.43, F(1,306)=54.63, p<.001$, $\left.\eta^{2}=.15\right)$. A significant interaction between brand competence and situational consistency qualified this main effect $(F(1,306)=$ $\left.14.45, p<.001, \eta^{2}=.05\right)$. In line with the second hypothesis, simple main effect analyses showed that the impact of brand competence was larger when the situation was consistent with the key association that the brand evoked $\left(M_{\text {competent brand }}=3.64\right.$, $\mathrm{SD}=.37$ vs. $M_{\text {incompetent brand }}=3.13, \mathrm{SD}=.45, F(1,306)=62.64$, $p<.001, \eta^{2}=.17$ ) than when the situation was inconsistent with the brand association, although the impact of brand competence was still significant in the latter case $\left(M_{\text {competent brand }}=3.52\right.$, $\mathrm{SD}=.41$ vs. $M_{\text {incompetent brand }}=3.36, \mathrm{SD}=.39, F(1,306)=6.44$, $p<.01, \eta^{2}=.02$ ).

Finally, a significant three-way interaction was observed between brand competence, situational consistency and time
Table 1

Means and standard deviations of perceived competence as a function of brand competence, situational context and time constraint

\begin{tabular}{|c|c|c|c|c|}
\hline \multirow[t]{3}{*}{ Situational context } & \multicolumn{4}{|c|}{ Brand competence } \\
\hline & \multicolumn{2}{|l|}{ High } & \multicolumn{2}{|l|}{ Low } \\
\hline & $M$ & SD & $M$ & $\mathrm{SD}$ \\
\hline \multicolumn{5}{|c|}{ Time constraint: present } \\
\hline Consistent & $3.65^{\mathrm{a}}$ & .38 & $3.20^{\mathrm{b}}$ & .47 \\
\hline Inconsistent & $3.62^{\mathrm{a}}$ & .40 & $3.32^{\mathrm{b}}$ & .38 \\
\hline \multicolumn{5}{|c|}{ Time constraint: absent } \\
\hline Consistent & $3.63^{\mathrm{a}}$ & .36 & $3.06^{\mathrm{b}}$ & .42 \\
\hline Inconsistent & $3.42^{\mathrm{a}}$ & .39 & $3.39^{\mathrm{a}}$ & .41 \\
\hline
\end{tabular}

Note. Means are on 5-point scales, with higher values indicating higher levels of perceived competence. Within each row, means with no superscripts in common differ significantly $(p<.05)$, as indicated by a least significant difference test for multiple comparisons between means (Kirk, 1982).

constraint $\left(F(1,306)=4.47, p<.05, \eta^{2}=.02\right)$. Additional contrast analyses revealed that the 2-way interaction between brand competence and situational consistency was indeed more pronounced when participants had ample time for their impression formation task. That is, when no time limit was imposed, the impact of brand competence was only significant when the situation was consistent $(F(1,306)=38.18, p<.001$, $\eta^{2}=.11$ ), not when the situation was inconsistent with the association the brand evoked $(F<1)$. In contrast, when subjects were confronted with a time limit for their impression formation task, brand competence affected perceptions of personal competence regardless of whether the situation matched ( $F(1$, $\left.306)=25.10, p<.001, \eta^{2}=.08\right)$ or mismatched the brand in its key association $\left(F(1,306)=11.01, p<.001, \eta^{2}=.04\right.$, see Table 1 for means for all conditions of the experiment).

\section{Discussion}

The present research tests the idea that "we are what we wear" at least in the eyes of an external perceiver. Earlier research supports the notion that branded items are capable of affecting the self (Belk, 1988) and self-perceptions of one's salient personality traits (Fennis et al., 2005). The present findings extend these results. Although the choice for a brand with a specific personality can certainly be a function of the personality of its owner, the present article proposes and demonstrates that a reverse process, by which the owner's personality is the dependent variable and brand personality the causal agent, is also likely. More specifically, in line with the continuum model of impression formation (Fiske and Neuberg, 1990; Fiske et al., 1990) brand attributes could directly affect perceptions of personality traits of the brand's presumed owner. A transfer effect is observed from a salient brand personality trait to perceptions of the personality of the owner of the brand. More specifically, all else being equal, someone wearing a competent brand is perceived to be more competent than someone wearing an incompetent brand. However, in the present study, all else is not equal. The transfer effect from brand personality to the target's personality is qualified in more than one way. In line with previous impression formation and persuasion research 
(Aaker and Sengupta, 2000; Maheswaran and Chaiken, 1991), the present research finds that the effect of brand personality on impression formation is stronger when the situational context is consistent with the key association the brand evokes, than when it is inconsistent. That is, the brand label is only deemed a valid indicator of the personality traits of the brand owner when the situation which features the owner does not "contradict" the brand association. Conversely, the impact of brand personality is considerably smaller (but not entirely attenuated) when there is a clear mismatch between brand and setting. In the present study, when the target wears a sweater with the "Boss" logo, it positively affects his perceived competence to a larger extent when he is situated on a golf course (a consistent situational context), than on a camping site (an inconsistent context). In many parts of the world, but certainly in the Netherlands where data collection for the present study took place, golf is played overwhelmingly by those that are well-off and successful. In contrast, spending a vacation on a camping site has more of a "blue-collar" connotation. Hence, brand competence items such as "leader" "successful", "confident" and "corporate" describe associations surrounding the golf course more accurately than the camping site. As a consequence, the "Australian" logo (the brand rated lowest in competence in the pilot test) has a larger negative influence on the target's perceived competence when he finds himself on the camping site.

This interaction effect between situational context and brand personality implies a careful integration by the perceiver of these different sources of information and applying them to infer something about the target. According to the continuum model this integration process demands considerable mental effort and conscious attention and the present data attest to this notion. A significant three-way interaction effect indicates that the impact of the integration of situational context and brand personality on impression formation is more pronounced when participants have ample time for the evaluation task. This suggests that integrating various sources of information indeed represents a form of piecemeal processing, or at least processing on the more individuating end of the impression formation continuum. As such, the continuum model propositions (and the present data supporting it) fit well with dual process models such as the ELM (Petty and Cacioppo, 1986) or HSM (Chaiken, 1980) in that all these frameworks discern a careful and effortful form of processing that requires considerable conscious attention, and a more limited and heuristic type of processing, that is sometimes akin to the concept of "mindlessness" forwarded by Langer (1992). Thus, the pattern of results found when participants are under no time constraint resembles the effortful mode. In contrast, the results of the additional contrast analyses also show that when subjects are bound by a fixed time interval in which they have to complete their judgment task, brand personality is still effective in influencing the perception of the target. This is in line with research suggesting that people resort to simple heuristics in judgment and decision making when they lack the ability to engage in more careful scrutiny of the information available for evaluation (cf. Chaiken and Trope, 1999).

The present findings are informative in several respects. First, studies in social and consumer psychology suggest that people often have an impression management motive in social interactions (see Sengupta et al., 2002), and that products and brands are sometimes used and displayed with the aim to create a favourable image. The current results show that consumers are very likely to succeed in their impression management goals, as impressions are indeed quite easily formed in line with the brand the owner displays. Hence, it appears to be quite easy to "dress for success" and get away with it.

The present set of findings also attests to the conceptual viability of the brand personality construct developed by Aaker (1997) in that its domains of operation appear to reach beyond the spheres that this author had designed for the concept. More specifically, Aaker (1997) argues that brand personality dimensions may affect consumer choice behavior as a result of selfexpressive needs (i.e., one chooses the brand that is a logical extension of the actual or ideal self). In Aaker's $(1997,1999)$ research, a person's self-concept remains in its role of independent variable. In the present case, this role reverses and the human personality structure serves as a dependent variable. Moreover, it is interesting to note that the concept of brand personality can be considered salient to such an extent, that it is capable of playing the same role that unequivocal, physical features have been found to play in impression formation (Biernat and Vescio, 1993; Hewstone et al., 1991). That is, although our participants are not informed of the brand personality concept, nor instructed to observe the brand logo depicted on the sweater worn by the target, the logo nevertheless exerted a strong and predicted impact on the perceived competence of the target. The present results, however, leave open several interesting venues for future research. For example, the study is restricted to perceived competence as a trait. However, brand competence may also influence other types of ascribed traits, for instance perceived conscientiousness or intelligence to mention but two plausible candidates from the Big-Five (Goldberg, 1992). Conversely, future research could investigate whether the effects found here, can be replicated using one or more of the other four dimensions of the brand personality construct.

Another issue pertains to the ecological validity of the findings. In the vignette used, the brand logo is quite conspicuous to our participants as it is shown prominently on the sweater the target wore. One could wonder whether effects on impression formation of comparable magnitude would be obtained when brand logos are invisible to the observer. This need not necessarily pose a restriction to the potential for generalizing the present findings, since a brand tends to manifest itself in more ways than only via the logo. The brand-specific use of colors, styling, lay-out, materials and other observable design features can all "betray" the brand even when the logo is not shown, and hence could impact impression formation to the same extent that the actual logo does. This constitutes an interesting possibility for future research.

In addition, the critical reader may infer that exposing participants to the word "Boss" could activate the concurrent stereotype which, presumably through a process of priming (e.g., Bargh et al., 2001), then affects competence ratings. However, several considerations argue against this position. First, since the 
study is conducted in the Netherlands, the stereotype involved would primarily be triggered by a Dutch, rather than an English word. Second, the brand logo includes more than just the word Boss. More specifically, underneath the word Boss, "Hugo Boss" is positioned in the logo, which diminishes the odds of a simple activation of the stereotype of a superior in charge (if such a unidimensional stereotype exists at all). Third, all brands for the reported pilot test, and the two brands employed in the actual experiment are chosen on the basis of their familiarity as clothing brands to the participants. This familiarity is further enhanced by the fact that all brands are actively marketed at the time of study. Nevertheless, although the current findings regarding the Boss logo are in all likelihood not the result of simple stereotype activation, this does not imply that priming phenomena as such should be ruled out as mediating constructs in the process of consumer impression formation (see DeCoster and Claypool, 2004). Exploring these processes more in depth should constitute a promising research domain.

From the perspective of consumer impression formation, additional studies could focus on the impact of other types of brands, for other product categories than the one used in the present study and in other types of situational contexts. In addition, to more fully explore the dynamics underlying the process of person perception, motivational factors such as personal relevance or outcome dependency could be varied in addition to the ability-related factor manipulated in the current study. Finally, as the proof of the pudding is in the eating, the present findings could be extended profitably by including actual behavior between target and perceiver. That is, would an impression formation process, influenced by brand personality traits, also carry over to affect the way interpersonal behavior between target and perceiver is shaped? Possibly. For example, impressions of a target's sincerity as a function of brand sincerity may induce a "trait-compatible" behavioral template influencing the actual interaction between target and perceiver (e.g., one characterized by honesty, and aimed at mutual understanding, see Aaker et al., 2004). Conversely, some brands could possibly evoke more hostile behavior in certain situations. For instance, in several communities debates are currently raging on prohibiting adolescents to wear certain brands of shoes and clothing, because they are thought to be associated with right-wing extremist political beliefs (e.g., "Lonsdale" clothing or "Dr. Marten's" shoes). Wearing these brands, especially in a situational context that matches the presumed brand association (e.g., a political riot or an otherwise "volatile" situation such as a gathering of football hooligans) could perhaps easily "ignite" patterns of interpersonal aggression. If these and other phenomena were to be demonstrated, it would attest to the power of brands in influencing feelings, thoughts and actual behavior among consumers, to the extent that brands may function as essential building blocks for social cognition and social interaction.

\section{Acknowledgements}

The authors thank Marieke Fransen, Moussa Faroek and Vincent Troupin for their input and assistance in data collection.

\section{References}

Aaker JL. Dimensions of brand personality. J Mark Res 1997;34(3):347-56.

Aaker JL. The malleable self: the role of self-expression in persuasion. J Mark Res 1999;36(1):45-57.

Aaker JL, Sengupta J. Additivity versus attenuation: the role of culture in the resolution of information incongruity. J Consum Psychol 2000;9(2):67-82.

Aaker J, Fournier S, Brasel SA. When good brands do bad. J Consum Res 2004;31(1):1-16.

Bargh JA, Gollwitzer PM, Lee-Chai A. The automated will: nonconscious activation and pursuit of behavioral goals. J Pers Soc Psychol 2001;81: 1014-27.

Belk RW. Possessions and the extended self. J Consum Res 1988;15(2):139-68.

Biernat M, Vescio TK. Categorization and stereotyping: effects of group context on memory and social judgment. J Exp Soc Psychol 1993;29:166-202.

Chaiken S. Heuristic versus systematic information processing and the use of source versus message cues in persuasion. J Pers Soc Psychol 1980;39: $752-66$.

Chaiken S, Trope Y, editors. Dual process theories in social psychology. New York: Guilford; 1999.

DeCoster J, Claypool HM. A meta analysis of priming effects on impression formation supporting a general model of informational biases. Pers Soc Psychol Rev 2004;8(1):2-27

Fennis BM, Pruyn AThH, Maasland M. Revisiting the malleable self: brand effects on consumer self-perceptions of personality traits. In: Menon G, Rao A, editors. Advances in Consumer Research, vol. 32. Provo, UT: Association for Consumer Research; 2005. p. 1-7.

Fiske ST, Leyens JP. Let social psychology be faddish, or at least heterogeneous. In: McCarty C, Haslam SA, editors. Message of social psychology: perspectives on mind in society. Oxford: Blackwell; 1996. p. 92-112.

Fiske ST, Neuberg SL. A continuum of impression formation, from categorybased to individuating processes: influences of information and motivation on attention and interpretation. In: Zanna MP, editor. Advances in Experimental Social Psychology, vol. 23. New York: Academic Press; 1990. p. 1-74.

Fiske ST, Lin M, Neuberg SL. The continuum model: ten years later. In: Chaiken $\mathrm{S}$, Trope Y, editors. Dual process theories in social psychology. New York: Guilford; 1990. p. 231-54

Fournier S. Consumers and their brands: developing relationship theory in consumer research. J Consum Res 1998;24(4):343-73.

Goldberg LR. The development of markers for the big-five factor structure. Psychol Assess 1992;4(1):26-42.

Haire M. Projective techniques in marketing research. J Mark 1950;14(5): 649-56.

Hewstone M, Hantzi A, Johnston L. Social categorization and person memory: the pervasiveness of race as an organizing principle. Eur J Soc Psychol 1991;21:517-28.

Kirk RE. Experimental design: procedures for the behavioral sciences. 2nd ed. Belmont, CA: Brooks/Cole; 1982.

Langer EJ. Matters of mind: mindfulness/mindlessness in perspective. Conscious Cogn 1992;1:289-305.

Levine GM, Halberstadt JB, Goldstone RL. Reasoning and weighting of attributes in attitude judgments. J Pers Soc Psychol 1996;70:230-40.

Maheswaran D, Chaiken S. Promoting systematic processing in lowinvolvement settings: effects of incongruent information on processing and judgment. J Pers Soc Psychol 1991;61:13-25.

Maheswaran D, Mackie DM, Chaiken S. Brand name as a heuristic cue: the effects of task importance and expectancy confirmation on consumer judgments. J Consum Psychol 1992;1:317-36.

Markus H, Kunda Z. Stability and malleability of the self-concept. J Pers Soc Psychol 1986;51(4):858-66.

Petty RE, Cacioppo JT. Communication and persuasion: central and peripheral routes to attitude change. New York: Springer; 1986.

Sengupta J, Dahl DW, Gorn GJ. Misrepresentation in the consumer context. J Consum Psychol 2002;12(2):69-79. 